\title{
The Chemical Input Status and Transformation Path of the Planting Industry in China
}

\author{
Yi Xiaoyan, Yuan Meng, Yin Changbin
}

Institute of Agricultural Resources and Regional Planning, Chinese Academy of Agricultural Sciences, Beijing 100081, China

\begin{abstract}
This study examined the total inputs and regional characteristics of chemical input in China since the 1990s, analyzed existing chemical input problems, and proposes a general transformational idea, transformational path, and security system for chemicals. Certain phenomena that result in obvious problems for the industry include the excessive use and low utilization rate of chemicals, regional imbalances in chemical input, imbalanced crops, and irrational crop structure within the planting industry. In addition, input methods need improvement. It is essential to transform the production mode by optimizing regional layouts, reforming planting systems, developing new chemicals, and adopting precise agricultural technologies. It is also necessary to strengthen support for and promote the green and sustainable development of farming based on scientific and technological innovation, integrated demonstrations, subsidy systems, standard specifications, and industry/university/research institute collaborations.
\end{abstract}

Keywords: planting industry; chemical input; transformational path; chemical fertilizers and pesticides; security system

\section{Introduction}

The 15th Plenary Session of the 18th Central Committee of the Communist Party of China incorporated ecological civilization construction into the five-year development plan for the first time. It proposes the five developmental ideas of "innovation, coordination, green, opening, and sharing." As one of the five developmental concepts, "green development" provides theoretical support for the green development of modern agriculture in China. The planting industry is an important part of agriculture. Among several considerations, the investment in agricultural chemicals has been a hot topic in governmental departments and academia. For a long time, the excessive use and unreasonable application of fertilizers and pesticides has not only led to an increase in agricultural production costs, but also problems such as soil compaction, food safety issues, and water pollution, which pose a threat to China's agricultural production environment and human health [1]. Hence, in 2015, the Ministry of Agriculture formulated a "zero growth" action for fertilizers and pesticides and set a goal of "zero growth" in chemical fertilizers and pesticides by 2020 . To achieve zero growth of fertilizers and pesticides, it is necessary to investigate the present situation of fertilizer and pesticide investment, analyze its key problems, identify a means to solve the problem, and propose relevant measures and suggestions. There are many types of chemicals used in crop production in China. This study focuses on chemical fertilizers and pesticides and discusses their input status and transformational path.

\section{Input status and characteristics of chemicals in the planting industry}

2.1 Total input and distribution of chemicals in the planting industry

Chemical fertilizer is an important means of production in agriculture. To increase the output of agricultural products, the use of chemical fertilizer is continuously increasing.

Received date: June 20, 2017; Revised date: July 18, 2017

Corresponding author: Yin Changbin, Institute of Agricultural Resources and Regional Planning, Chinese Academy of Agricultural Sciences, Professor. Major research field is utilization and management of agricultural resources. E-mail: yinchangbin@caas.cn

Funding program: CAE Advisory Project “Several Strategic Issues on Eco-Civilization Construction (Phase II)" (2015-ZD-16)

Chinese version: Strategic Study of CAE 2017, 19 (4): 124-129

Cited item: Yin Changbin et al. The Chemical Input Status and Transformation Path of the Planting Industry in China. Strategic Study of CAE, https://doi.org/10.15302/ J-SSCAE-2017.04.020 
As shown in Table 1, the amount of chemical fertilizer used in China (reduced purity) increased from $2.5903 \times 10^{7} \mathrm{t}$ in 1990 to $6.0226 \times 10^{7} \mathrm{t}$ in 2015 , at an average annual growth rate of $3.3 \%$. In terms of regional distribution, East China and Central China are fertilizer-intensive areas. The total amount used in 2015 was $2.7835 \times 10^{7} \mathrm{t}$, accounting for $46.2 \%$ of that used in the country. Among the two regions, the total amount of chemical fertilizer applied in East China was $1.487 \times 10^{7} \mathrm{t}$, accounting for $24.7 \%$ of that used in China, and the total amount of fertilizer applied in Central China was $1.2965 \times 10^{7} \mathrm{t}$, accounting for $21.5 \%$ of that used in the country. In terms of provinces, Henan and Shandong are those with the highest fertilizer application, accounting for $19.6 \%$ of the total fertilizer application in 2015, as shown in Table 2.

Pesticides play an important role in protecting agricultural production, improving the agricultural comprehensive production capacity, promoting agricultural product stability, and increasing farmer income. It is an indispensable means of production in modern agriculture. However, the application of pesticides has grown rapidly during the last decade, from $7.65 \times 10^{5} \mathrm{t}$ in 1995 to $1.807 \times 10^{5}$ in 2004 . The average annual growth rate is $3.6 \%$. Similar to chemical fertilizers, the amount of pesticides used in East and Central China has been higher than that in other areas. In 2014, the amount of pesticides used in East China and Central China was $5.65 \times 10^{5} \mathrm{t}$ and $3.8 \times 10^{5} \mathrm{t}$, accounting for $31.3 \%$ and $21.0 \%$ of the country, respectively, as shown in Table 1 .

\subsection{Input status of major crop chemicals}

According to the 2016 "National agricultural product cost-benefit" data, studies have estimated that China's economic crops, such as fruits and vegetables, use far more chemical fertilizers and pesticides than crops such as grain. In 2015 , the average fertilizer application to three grains in China was $367.8 \mathrm{~kg} \cdot \mathrm{hm}^{-2}$, while for vegetables it was $517.8 \mathrm{~kg} \cdot \mathrm{hm}^{-2}$. This is 1.41 times greater than food (Table 3). Other cash crops, such as cotton, sugar cane, citrus fruits, and apples, also are provided more fertilizer than grain. Regarding the use of pesticides, the expenditure of pesticides in cash crops (because there is no statistical data to support the amount of pesticide usage, pesticide expenditure is used instead to compare the use among different crops) is higher than that for grain. The average pesticide expenditure of citrus is 8042.25 yuan per hectare, 18 times that of food crops (Table 3).

According to the monitoring statistics of the national agricultural technology popularization center, the average amount of pesticide used in crop farming in China from 2010 to 2014 was $3.172 \times 10^{5} \mathrm{t}$. Among this use, the field crop application was $1.981 \times 10^{5} \mathrm{t}$, the application to fruits and vegetables was $9.25 \times 10^{4} \mathrm{t}$, and that to other crops was $2.67 \times 10^{4} \mathrm{t}$ (Table 4). Although the total amount of application to fruits and vegetables was less than that of field crops, the amount of application to fruit and vegetable crops per unit area was greater than that of the field crops. Herbicide is the most widely used pesticide in China, accounting for approximately $60 \%$, insecticide is near $30 \%$ and biological pesticide is the least used, only accounting for $7.83 \%$. Because of the unreasonable means of pesticide application, the utilization rate of pesticides in China is less than $30 \%$, and the pesticides in the soil are washed into rivers, lakes, and seas via irrigation water or rain. This runoff leads to water pollution. The

Table 1. Amount of chemical fertilizer and pesticide used in various regions (reduced purity)

\begin{tabular}{|c|c|c|c|c|c|c|c|c|c|}
\hline & Year & Nationwide & North China & $\begin{array}{c}\text { Northeast } \\
\text { China }\end{array}$ & East China & Central China & $\begin{array}{l}\text { South } \\
\text { China }\end{array}$ & $\begin{array}{c}\text { Southwest } \\
\text { China }\end{array}$ & $\begin{array}{c}\text { Northwest } \\
\text { China }\end{array}$ \\
\hline \multirow{4}{*}{$\begin{array}{l}\text { Chemical } \\
\text { fertilizer }\end{array}$} & 1990 & 2590.3 & 257.6 & 242.6 & 891.3 & 487.9 & 260.8 & 288.3 & 161.8 \\
\hline & 2000 & 4146.4 & 466.9 & 343.4 & 1351.1 & 848.7 & 360.2 & 470.5 & 305.6 \\
\hline & 2010 & 5561.7 & 649.7 & 537.8 & 1498.9 & 1242.5 & 520.9 & 615.7 & 496.3 \\
\hline & 2015 & 6022.6 & 715.7 & 638.6 & 1487 & 1296.5 & 567.5 & 689.1 & 628.2 \\
\hline \multirow{3}{*}{ Pesticide } & 2000 & 128 & 10.8 & 8.5 & 49.7 & 29.7 & 14.1 & 11.3 & 3.9 \\
\hline & 2010 & 175.8 & 14.3 & 18.6 & 60.8 & 38.4 & 21.4 & 14.3 & 8 \\
\hline & 2014 & 180.7 & 15.5 & 20.7 & 56.5 & 38 & 22.5 & 14.9 & 12.6 \\
\hline
\end{tabular}

Calculation is based on the China Statistical Yearbook (over years).

Table 2. Application of chemical fertilizers in major provinces during recent years.

\begin{tabular}{lccc}
\hline Year & Henan $\left(\times 10^{4} \mathrm{t}\right)$ & Shandong $\left(\times 10^{4} \mathrm{t}\right)$ & Proportion of the whole country $(\%)$ \\
1990 & 213.2 & 245.5 & 17.7 \\
2000 & 419.5 & 423.2 & 20.3 \\
2010 & 655.2 & 475.3 & 20.3 \\
2015 & 716.1 & 463.5 & 19.6 \\
\hline
\end{tabular}

Calculation is based on the China Statistical Yearbook (over years). 
unreasonable use of pesticides will lead to pesticides remaining on the crops over a certain period of time, resulting in an increase in pesticide residues on agricultural products, in turn affecting people's health

\section{Existing problems in the chemical input in the planting industry}

\subsection{Excessive input and low utilization}

Chemical input plays a significant role in increasing agricultural production, and studies show that fertilizers contribute a $40 \%-50 \%$ increase in grain production [2]. However, excessive use of chemicals not only reduces the utilization rate of the resource, but also causes environmental pollution. In 2015, the total amount of fertilizer applied in China reached $6.0226 \times 10^{7} \mathrm{t}$. It has increased $26.4 \%$ from $4.7662 \times 10^{7} \mathrm{t}$ in 2005 . In 2015 , the total amount of pesticide applied reached $1.807 \times 10^{6} \mathrm{t}$. It has increased $22.5 \%$ from $1.46 \times 10^{6} \mathrm{t}$ in 2005 .

There is an obvious over-application of chemical fertilizers in China. The average application of chemical fertilizer per hectare on crops in China is $328.5 \mathrm{~kg}$, which is much higher than of the average of $120 \mathrm{~kg}$ for the remainder of the world. China's use is 2.6 times that of the United States and 2.5 times that of the European Union. The average amount of pesticide used in China is $596.25 \mathrm{~kg} \cdot \mathrm{hm}^{-2}, 2.5$ times the world average. In addition, the utilization rate of chemical fertilizers and pesticides in China is less than $30 \%$, and there is still a large gap with developed countries. Nitrogen use efficiency of food crops in the United States

Table 3. Input of Major Crop Chemicals.

\begin{tabular}{lcc}
\hline Crop variety & $\begin{array}{c}\text { Chemical fertilizer } \\
\left(\mathrm{kg} \cdot \mathrm{hm}^{-2}\right)\end{array}$ & $\begin{array}{c}\text { Pesticide } \\
\left(\text { yuan } / \mathrm{hm}^{2}\right)\end{array}$ \\
\hline Paddy & 333.15 & 767.40 \\
Wheat & 405.75 & 295.05 \\
corn & 364.50 & 249.15 \\
Cotton & 570.15 & 1062.30 \\
Sugarcane & 924.75 & 891.00 \\
Apple & 969.90 & 3919.50 \\
Citrus & 1012.80 & 8042.25 \\
Vegetable & 517.80 & 1955.40 \\
\hline
\end{tabular}

is approximately $50 \%$, and that in major European countries is approximately $65 \%, 15 \%$ to $30 \%$ higher than China. In the developed countries of Europe and the United States, the pesticide utilization rate of wheat, corn, and other food crops is $50 \%$ to $60 \%, 15$ to $25 \%$ higher than that in China. The amount of chemical fertilizer applied to fruit trees and vegetables in China has exceeded a safe level. It is estimated that the amount of chemical fertilizer applied to fruit trees and vegetables across 60 million $\mathrm{hm}^{2}$ in China is $5 \times 10^{6} \mathrm{t}$ greater than that applied to grain across 106.6 million $\mathrm{hm}^{2}[3]$.

\subsection{Regional imbalance, crop imbalance, and structural irrationality}

In terms of regional distribution, the eastern economically developed areas, the lower reaches of the Yangtze River, and the urban suburbs have the highest application rate. The total amount of chemical fertilizer applied in East and Central China in 2015 was $2.7835 \times 10^{7}$ t, accounting for $46.2 \%$ of the country's total amount. Pesticide use in East China and Central China has also been higher than in other areas. In 2014, the amount of pesticides used in East China and Central China was $5.65 \times 10^{5} \mathrm{t}$ and $3.8 \times 10^{5} \mathrm{t}$, accounting for $31.3 \%$ and $21.0 \%$ of the country's total amount, respectively.

In terms of crop type, the amount of fertilizer and pesticide used in food crops, fruits, and vegetables has increased in turn. Fruit and vegetable growers have higher vigilance and awareness of crop yield and pest control than grain growers and they use more fertilizer and pesticide. On the one hand, the use is related to the nature of the crops and the diseases and insect pests. On the other hand, the yield of food crops is low and the input of farmers is low, as well. In contrast fruit and vegetable yields are high; farmers invest heavily in fertilizers, pesticides, and manual labor; and they are more active in pest control during the early stage of growing. As a result, pesticides are used more frequently and in greater quantities.

In terms of input structure, the imbalance of the fertilizer input structure is obvious. The ratio of nitrogen, phosphorus, and potassium is not coordinated, and the percentage of organic fertilizer in the fertilizer is low. As can be seen from Table 5, although the proportion of nitrogen and phosphorus fertilizer is decreasing slowly annually, and the proportion of potassium and

Table 4. Application rate of pesticides for crop production in China from 2010 to 2014

\begin{tabular}{lccccc}
\hline Year & Total $\left(\times 10^{4} \mathrm{t}\right)$ & Field crop $\left(\times 10^{4} \mathrm{t}\right)$ & Fruit and vegetable crop $\left(\times 10^{4} \mathrm{t}\right)$ & Other crops $\left(\times 10^{4} \mathrm{t}\right)$ & Bio-pesticide proportion $(\%)$ \\
\hline 2010 & 31.28 & 20.13 & 8.56 & 10.27 & 2.59 \\
2011 & 32.36 & 19.37 & 9.19 & 2.62 & 2.73 \\
2012 & 32.44 & 20.53 & 9.16 & 2.74 \\
2013 & 31.72 & 19.82 & 9.07 & 2.67 & 7.61 \\
2014 & 30.92 & 19.18 & 9.25 & 2.67 \\
Average & 31.72 & 19.81 & 7.83 & 7.27 \\
\hline
\end{tabular}


compound fertilizer is increasing annually, great problems remain in the fertilization structure [4]. The input of organic fertilizer is obviously insufficient, and according to the National Agricultural Technology Extension Service Center, the proportion of organic fertilizer in the total fertilizer input is continuously decreasing, from $99.9 \%$ in 1949 , to $37.4 \%$ in 1990 , and to $39.6 \%$ in 2000. Data from the China Environmental Bulletin 2004 showed the amount of organic fertilizer applied in China was only $25 \%$ of the total amount of fertilizer applied in 2003, and it has continued to show a decreasing trend in recent years. In addition, the structure of pesticide application is not entirely reasonable, since the advent of organ chlorine pesticides, chemical pesticides have rapidly developed.

\subsection{Input mode in need of improvement}

In China, the planting industry is mainly distributed management, because of the outdated concepts of farmers and the lag in technical extension and other service systems, farmers are still giving priority to traditional methods of fertilizer and pesticide use. It is very common to apply a large amount of irrigation water and phosphate fertilizer after fertilization, which causes nutrient loss. The development and popularization of effective fertilizer application techniques are very weak, and mechanical fertilization and biological pesticides have not yet been popularized [5]. The production habit of farmers is to use a high input of chemical fertilizers and pesticides in exchange for a high output of agricultural products. Unscientific input makes harvesting less efficient. Under the condition of low planting benefit and increasing environmental capacity, it is no longer possible to develop agriculture by investing abundant resources and consuming the environment [6]. There is an urgent need to change the means of development and promote more efficient, scientifically based fertilizer and pesticide use.

\section{Thinking and path selection of chemical input transformation in the planting industry}

\subsection{General idea}

Running through the five major development concepts of "innovation, coordination, green, opening, and sharing," is the aim to ensure national food security and an effective supply of important agricultural products including (1) adhering to green, low-carbon, recycling development, resource conservation, and environmental protection; (2) relying on scientific and technological progress and mechanism innovation; (3) depending on new agricultural management entities and socialized service organizations; (4) pushing forward the transformation of the crop production mode and the upgrading the green transformation; (5) comprehensively promoting the precision, reduction and safety of chemical input in crop production; (6) expanding the pilot scale of crop rotation and improving the input structure of chemicals in the planting industry; (7) vigorously promoting the combination of planting and breeding and (8) encouraging the use of organic fertilizer, instead of chemical fertilizer, and bio-pesticides that are safe and of low toxicity to improve the utilization efficiency of agricultural inputs and ensure the quality and safety of agricultural products.

\subsection{Transformational path}

4.2.1 Optimizing the planting structure to form a production pattern matching the regional environmental capacity

Carrying out the theory of innovation and development in depth, the strategy of "store grain in the ground, store grain in technology" should be implemented. Basically self-sufficient grain and rations that are absolutely safe should be ensured. Supply-side structural reform should be promoted providing full consideration to the principle of regional input for balance. Regional distribution should be optimized, the adjustment of planting structure promoted, and a new model of green agricultural development established that matches the regional environmental capacity. The aforementioned should be completed in accordance with the overall deployment Guidelines on the Establishment of Functional Areas for Grain Production and Important Agricultural Product Protection Zones (hereinafter referred to as the two zones) and the National Planting Structure Adjustment Plan (2016-2020) issued by the state Council. Considering the carrying capacity of resources, environmental capacity, ecological types, and developmental basis, the developmental direction and emphasis of different regions can be determined. There are different strategies according to different types to construct a scientific, rational, and specialized production pattern [7]. On the one hand,

Table 5. Application of various fertilizers in recent years.

\begin{tabular}{|c|c|c|c|c|c|c|c|c|c|}
\hline \multirow[b]{2}{*}{ Year } & \multicolumn{2}{|c|}{ Nitrogen fertilizer } & \multicolumn{2}{|c|}{ Phosphate fertilizer } & \multicolumn{2}{|c|}{ Potash fertilizer } & \multicolumn{2}{|c|}{ Compound fertilizer } & \multirow[b]{2}{*}{$\begin{array}{l}\text { Proportion of organic } \\
\text { fertilizer }(\%)\end{array}$} \\
\hline & $\begin{array}{c}\text { Application } \\
\text { amount } \\
\left(\times 10^{4} \mathrm{t}\right)\end{array}$ & $\begin{array}{l}\text { Proportion } \\
\quad(\%)\end{array}$ & $\begin{array}{l}\text { Application } \\
\text { amount } \\
\left(\times 10^{4} \mathrm{t}\right)\end{array}$ & $\begin{array}{l}\text { Proportion } \\
\quad(\%)\end{array}$ & $\begin{array}{l}\text { Application } \\
\text { amount } \\
\left(\times 10^{4} \mathrm{t}\right)\end{array}$ & $\begin{array}{l}\text { Proportion } \\
\quad(\%)\end{array}$ & $\begin{array}{l}\text { Application } \\
\text { amount } \\
\left(\times 10^{4} \mathrm{t}\right)\end{array}$ & $\begin{array}{l}\text { Proportion } \\
\quad(\%)\end{array}$ & \\
\hline 1990 & 1638.4 & 63.3 & 462.4 & 17.9 & 147.9 & 5.7 & 341.6 & 13.2 & 37.4 \\
\hline 2000 & 2161.5 & 52.1 & 690.5 & 16.7 & 376.5 & 9.1 & 917.9 & 22.1 & 30.6 \\
\hline 2010 & 2353.7 & 42.3 & 805.6 & 14.5 & 586.4 & 10.5 & 1798.5 & 32.3 & - \\
\hline 2015 & 2361.6 & 39.2 & 843.1 & 14 & 642.3 & 10.7 & 2175.7 & 36.1 & - \\
\hline
\end{tabular}


it is necessary to increase the production capacity in the main production areas and focus on developing the high-quality grain and oil production areas in the northeast plain, the Huang-Huai-Hai region, and the middle and lower reaches of the Yangtze River; the cotton region in Xinjiang; and the sugarcane dominated regions in Guangxi and Yunnan. Vegetables grown in the south should be transported to northern bases and to facilitate vegetable growing in the north. Infrastructure construction should be increased and the capacity steadily increased. On the other hand, we should delimit and establish "two zones": establish a grain production function area on the northeast plain, the Huang-Huai-Hai area, the middle and lower reaches of the Yangtze River, the southeast coast, the northwest, and the southwest area. Important agricultural reserves in which soybeans are the focus should be established in the northeast, with cotton in Xinjiang, rape along the Yangtze River, and sugar in Guangxi and Yunnan.

4.2.2 Push forward the reform of the planting system and realize a combination of land use and land cultivation

At present, grain production in most areas of China occurs twice a year, and for land in the south three times a year. The long-term high-load use of the land and the lack of soil rehabilitation have affected sustained and stable grain production [8] By providing fallow periods and rotating cultivated land, the intensity of exploitation and the input of chemical fertilizer and pesticide is reduced, which is beneficial for the elimination of agricultural pollution and the relief of ecological environmental pressure including improving soil fertility. Since 2014, China has explored arable land cropping systems in some areas, to explore a combination of land use and land cultivation and the land and grain supply and demand adjustment interaction. In areas where conditions are ripe to carry out two years of three-system reform, it would not only result in effective conservation of water resources, but also would be conducive to land recuperation, changing "eat dry pressing" to "Store grain in the ground." Learning from the experience of developed countries in Europe and America, such as Germany, which requires farms to have at least three crop rotations, plant green manure, etc., to cultivate soil fertility, improve soil quality, and achieve sustainable use of cultivated land resources.

4.2.3 Increase research and development of new agricultural chemicals to reduce environmental pollution

Scientific research should be intensified to develop highly selective, highly active biological agents and high-efficiency, low-toxicity, and low-residue pesticides. Publicity and technical promotion to reduce dependence on chemical pesticides should be increased. New products should be developed, and the recovery of recyclable products increased. On the premise of low toxicity, high efficiency, greening, and safety, we should advocate for the development of green ecological agriculture. At present, slow/controlled release fertilizer is favored as a new type of fertilizer. It has the characteristics of less environmental pollution, good fertilizer effect, and high economic benefits [9]. The development of new pesticides has been developing in a direction of low toxicity, low residue, high specificity, and no collateral damage. The popularization of new technologies can improve the efficiency of farm work and advance the quantity and quality of agricultural products. Agricultural chemicals can be used quickly and reasonably.

4.2.4 Promoting the application of precision agriculture steadily to improve the efficiency of resource utilization

Precision agriculture is the new trend for agricultural development in the world today, a synergy of the precise application of agricultural science, technology and multiple disciplines, it is a modern agricultural production management technology of sound science, technology content, and strong integration [10]. At present, China's agriculture is still at a critical moment of transformation and upgrading. Developing precision agriculture, comprehensively improving labor productivity, land productivity, the utilization rate of soil, and water and fertilizer resources are the key measures to change the agricultural development mode and promote green sustainable development [11]. The scale and mode of agricultural operation in China vary, and different precision agricultural models should be adopted according to local conditions. We should encourage those who have suitable conditions to attempt the change first. We should promote the industrialization of precision agricultural technology via the rapid transformation of scientific and technological achievements, establish a model of precision fertilization and pesticide application, and achieve specialization of agricultural production decisions. In addition, ecological protection and social economic development should be considered to realize the marketization of the allocation of agricultural resources.

\section{Safeguard system}

\subsection{Strengthen scientific and technological innovation, and promote the optimization, transformation, and upgrading of planting structure}

We should promote scientific and technological innovation and technological integration innovation and strive to create an upgraded version of the green production model. We should vigorously promote the improvement of crop quality and efficiency, improve varieties and quality, and create brands and advance quality and efficiency. We should also push forward research and development of new technology which can reduce chemical fertilizer and pesticide usage, establishing production technology combined with agricultural machinery and agronomy. Research and development of agricultural biotechnology, information technology, food engineering technology, and other high-tech solutions should be encouraged. We should continuously enhance the capability of independent innovation in agricultural 
science and technology, focusing on developing new agricultural varieties and technologies with independent intellectual property rights.

\subsection{Increasing integration and demonstration of environment-friendly planting techniques}

We should intensify technological integration, aiming at the goals of greening, environmental protection, energy conservation, and cost-saving, and focusing on the need of structural reform of the agricultural supply. Along the whole industrial chain, efficient utilization of resources, fertilizer and pesticide reduction, full mechanization, agricultural information and other fields, extensive integration of advanced practical technology should be applied. We should strengthen the demonstration, promotion, training, and service of technological models to provide technical support for the development, transformation, and upgrading of modern agricultural industries. Research of green techniques for increasing agricultural production and efficiency, green techniques for preventing and controlling pests and diseases, cleaner production techniques for agriculture, and techniques for ecological recycling agriculture should be intensified [12]. Integrated research, the establishment and improvement of technological innovation, and the demonstration and popularization of a system for promoting agricultural development should be carried out. A group of demonstration areas of green agriculture and ecological recycling agriculture in light of local conditions should be constructed.

\subsection{Establish a green ecologically oriented agricultural support policy}

On the premise of ensuring national food security and stable growth of income, we should adhere to advancing steadily and adjusting gradually, taking reform and sound subsidy policy as the starting point. We should emphasize green ecological guidance and accelerate the implementation of relevant agricultural subsidy policy reform. Subsidies for major ecosystems such as arable land, grasslands, forestry, and wetlands should be increased. We should explore effective support policies for heavy metal pollution control on cultivated land, agricultural pollution control, and efficient water conservation in agriculture ${ }^{[13]}$. We should upgrade our policy objectives from quantity-based growth to quantity-based quality and ecology. Agricultural support policy has shifted to encouraging the economical use of agricultural resources and environmental protection and exploring the operating mechanism of adopting the end product subsidy system.

\subsection{Construct relevant technical standards and specification systems}

We should establish a system of standards, norms, and reg- ulations for sustainable development of agriculture. We should strictly restrict producers' behavior and strengthen safe application of agricultural chemicals, system construction of production process management, and postpartum link quality management [14]. We should put forward and formulate relevant regulations for field landscapes, biodiversity, and soil quality. We should improve the whole society's understanding of agricultural environmental protection and promote the healthy and steady development of agriculture. We can earn from the relevant standards and norms of developed countries in the field of agricultural sustainable development.

5.5 Strengthen the combination of production, research, and study to cultivate new professional farmers

We should adjust the focus of research, and organize and coordinate the relationship among production, research, and study. We should stablish a system and operating mechanism for promoting agricultural scientific and technological innovation [15]. We should create a scientific, developed, achievement transformation and demonstration of the application of an integrated agricultural science and technology industry chain such that agricultural research institutions form a close technical alliance. Realizing the sharing of scientific and technological resources via a market mechanism, we should shift from single technology research and development to integrated innovation, and gradually establish an integrated innovation system for agricultural science and technology to meet the needs of China's development and international competition.

\section{References}

[1] Yang H Q, Xu Y H. Status and restrictive factors of China's planting and its countermeasures [J]. Acta Agriculture Jiangxi, 2010, 22(8): 181-183. Chinese.

[2] Li J, Li J Y. Fertilizer using efficiency of China's grain production and its determining factors [J]. Research of Agricultural Modernization, 2011, 32(5): 565-568. Chinese.

[3] Liu R. The characteristics, control measures and suggestions of chemical input products in current agricultural production - A case study of Hunan province [J]. Review of Economic Research, 2013(43): 35-41. Chinese.

[4] Cai R. Agri-chemicals inputs and its impact on environment [J]. China Population, Resources and Environment, 2010, 20(3):107-110. Chinese.

[5] Du J, Luo J. Status and reasons of China's agricultural environmental pollution and its countermeasures [J]. Research of Agricultural Modernization, 2013, 34 (1): 90-94. Chinese.

[6] Rao J, Xu X Y, Ji X T. Status and occurrence mechanism of China's agricultural non-point pollution and its countermeasures[J]. Issues in Agricultural Economy, 2011(8): 81-87. Chinese.

[7] Qian Y, Chen J N. China's regional rational allocation of agricultural resources, comprehensive management of the environment and agricultural regional coordinated development strategy: system analysis 
and comprehensive management of agricultural environmental pollution [M]. Beijing: China Agriculture Press, 2008. Chinese.

[8] Zhang M K. Discussion on Sustainable Prevention and Control policy and technology of agricultural non - point pollution in China [J]. Journal of Zhejiang Agricultural Sciences, 2015, 56(1): 10-14. Chinese.

[9] Huang C Y. Feasibility and countermeasures of chemical pesticide dosage reduction [J]. Heilongjiang Agricultural Sciences, 2015(11): 145-147. Chinese.

[10] Jiang A N, Guan J H, Huang W J, et al. Benefit analysis on the precision fertilization of winter wheat for three consecutive years [J]. Journal of Sichuan Agricultural University, 2014, 32(3): 335-339. Chinese.

[11] Song C X, Ma H Y, Huang J K, et al. The effects of climate change and farmers' adaptability on wheat irrigation efficiency: an empirical study based on the main wheat production areas in the middle east of China [J]. Journal of Agro technical, 2014(2): 4-16. Chinese.
[12] Xiao X H, Liu C, Yang C H, et al. The demonstration and effect of integration of rice diseases' specialized and unified plant protection and Green Control [J]. South China Agriculture, 2016, 10(1): 6-9. Chinese.

[13] Zhang G H, Fei Y H, Liu C H, et al. Adaptation between irrigation intensity and groundwater carrying capacity in north China plain $[\mathrm{J}]$. Transactions of the Chinese Society of Agricultural Engineering, 2013, 29(1): 1-10. Chinese.

[14] Ge J H, Zhou S D. Whether the market distortion of the factor has stimulated agricultural pollution - taking fertilizer as an example [J]. Issues in Agricultural Economy, 2012(3): 92-98. Chinese.

[15] Ying R Y, Zhu Y. The impact of agricultural technology training on farmers' application of agricultural chemical inputs - evidence from experimental economics [J]. China Rural Survey, 2015(1): 50-58. Chinese. 